\title{
Fatalism as a Metaphysical Thesis
}

\author{
Ulrich Meyer \\ Colgate University \\ Philosopby Department \\ Hamilton, NY 13346, USA \\ umeyer@colgate.edu
}

\section{Article info}

CDD: 110

Received: 20.11.2016; Accepted: 21.11.2016

DOI: http://dx.doi.org/10.1590/0100-6045.2016.V39N4.UM

Keywords:

Fatalism

Determinism

Open Future

Thin red line

\section{ABSTRACT}

Even though fatalism has been an intermittent topic of philosophy since Greek antiquity, this paper argues that fate ought to be of little concern to metaphysicians. Fatalism is neither an interesting metaphysical thesis in its own right, nor can it be identified with theses that are, such as realism about the future or determinism.

\section{Introduction}

An agent $X$ was fated to $\varphi$ (in the past) just in case $\varphi$-ing was inevitable for $X$. The agent $\operatorname{did} \varphi$ and there was nothing that he could have done that would have prevented it. Similar for fates that have not yet come to pass. An agent is fated to $\varphi$ (in the future) just in case he will $\varphi$ and there is nothing that he could do between now and then that would prevent it. As I propose to understand the thesis, fatalism claims that some things are fated for some people. Like skepticism, fatalism thus comes in degrees. Just as one can be a skeptic about one area of inquiry but not about another, not everything that happens to $X$ needs to be fated, and the degree to which $X$ 's life is fated might

Manuscrito - Rev. Int. Fil. Campinas, v. 39, n. 4, pp. 203-223, out.-dez. 2016. 
differ from that of another agent $Y$. Radical fatalism is the thesis that everything is fated for everyone.

There is a familiar difficulty in spelling out what it is for a claim to be about a particular object. ${ }^{1}$ Similar problems arise here. Things that are fated for $X$ are about him in that they are things that he does or that happen to bim. To a first approximation, acceptable substitution instances for $\varphi$ are therefore transitive and intransitive verbs with $X$ as subject or object. An agent might thus be fated to die, or to be slapped by agent $Y$. There are also fates whose descriptions have higher logical complexity, such as being fated to remain an average soccer player. Just as it is not clear what it takes for a logically complex sentence to be about a particular object, it is not obvious what it takes for such a complex $\varphi$-ing to happen to a particular person. A rigorous account of fatalism would need to say more about this issue, but this problem can be ignored for current purposes. Just as a rough-and-ready understanding of 'about' suffices for most applications, the details of $\varphi$ do not matter much for the questions that I am interested in.

Agents have a prudential interest in their own fates, and in those of people they care about. It is less obvious whether fate matters to philosophy. Those who believe that fatalism is an interesting metaphysical thesis tend to think that there are fundamental aspects of reality that impose systematic constraints on people's fates. One famous example is Aristotle's sea battle argument, which tries to identify radical fatalism with realism about the future. More recently, radical fatalism has often been identified with the claim that the laws of nature are deterministic. There is also the theological doctrine of predestination, according to which people's fates are determined by the will of God.

I want to argue that these views are mistaken, and that fatalism matters little to metaphysics. This is not to deny that some people are fated to do certain things, or that people's fates depends on what the world is like. My claim is rather that fatalism is neither a metaphysically interesting thesis in it own right, nor can it be identified with theses that are, such as realism about the future or determinism. While the existence of an all-powerful God would be of metaphysical interest, the extent to which He would determine our fate is not. The degree of fatedness itself is not a metaphysically important feature

${ }^{1}$ See, e.g., Putnam (1958), Goodman (1965), Rescher (1963), and Yablo (2014).

Manuscrito - Rev. Int. Fil. Campinas, v. 39, n. 4, pp. 203-223, out.-dez. 2016. 
of the world we live in. Fate might matter to how we live our lives, but not to our metaphysics.

\section{Realism about the Future}

Realists about the future contend that there are times that are later than the present, and that each sentence $\varphi$ is either true or false at each of these instants. To talk about what will be true, a realist might introduce a future tense operator ' $F$ ' ("it will be the case that"), which is governed by the stipulation that ' $F \varphi$ ' is true at a time if and only if $\varphi$ is true at some later time. What makes this view realist is that all claims about the future have determinate truth-values. Given any claim $\varphi$, either ' $F \varphi$ ' or ' $F \neg \varphi$ ' is true. It might also be that both claims are true. If it is sunny tomorrow and rainy the day after then it is true that it will rain and that it will not. But one can ensure that only one of ' $F \varphi$ ' and ' $F \neg \varphi$ ' is true by packing enough descriptive content into $\varphi$, say, by adding a conjunct that describes the relative positions of earth, sun, and moon.

Anti-realists about the future disagree. They believe that it has not yet been settled what the future will be like, and that there are claims $\varphi$ for which neither ' $F \varphi$ ' nor ' $F \neg \varphi$ ' is true. They deny the existence of future times at which all sentences take definite truth-values. One popular way of modeling this alleged openness of the future is in terms of a branching time series. There are many different ways things might turn out, and thus many possible futures that branch off in different directions from the present. The future is open in that it has not yet been determined which of these possible futures will be the actual future. This is not the same as saying that there are no truths about the future. If $\varphi$ is necessary-in whatever sense of 'necessary' we used to spell out the notion of a possible future- then $\varphi$ is true in all possible futures, and is guaranteed to come to pass. So ' $F \varphi$ ' is true whenever $\varphi$ is necessary. But if $\varphi$ is contingent then $\varphi$ is true in some possible futures and false in others. In that case, neither ' $F \varphi$ ' nor ' $F \neg \varphi$ ' are true because it has not yet been settled which possible future will be the actual one. So we longer get the law of excluded middle for future tense claims, $F \varphi \vee F \neg \varphi$, which is a theorem schema of standard tense logic.

Manuscrito - Rev. Int. Fil. Campinas, v. 39, n. 4, pp. 203-223, out.-dez. 2016. 
Anti-realists disagree about how to adjust our logical framework to accommodate this feature. Popular proposals include truth-value gaps, which would not assign future contingents any truth-value at all (Thomason 1970); a three-valued logic that would assign them a truth-value that is neither True nor False (Lukasiewicz 1970; Prior 1953; Bourne 2004); and the denial of truth-functionality (Tooley 1997). Since anti-realists might also use different notions of necessity to spell out the notion of a possible future, this means that there is a broad spectrum of anti-realist positions to choose from. Luckily, the details do not matter for our purposes. The important points are: that ' $F \varphi$ ' is true if and only if $\varphi$ is true in all possible futures, and that no contingent claim about the future counts as true or false. This is what the openness of the future is supposed to consist in.

Anti-realism about the future must be not be confused with the view that time itself has future-directed branches. The view under consideration is antirealism about a single future, not realism about many futures. One difference between the two is that branch-realists would say that ' $F \varphi$ ' is true just in case $\varphi$ is true at some time later than the present. That is, ' $F \varphi$ ' is true if and only if $\varphi$ is true at some time in some future history. All future tense claims are either true or false, and there is nothing unreal or undetermined about the multiple futures. While anti-realists read ' $F$ ' as "in all future histories," branchrealists read it as "in some future history." This might look like a semantic disagreement about the future tense operator, but this is not really what is at issue. The main disagreement concerns the nature of future histories. For the branch-realist, future histories are part of the fully determined, branching future. All of the branches are as real as the past. Anti-realists, by contrast, do not think that the future has any branches. Their possible futures are not actual futures, but are only supposed to model the openness of a single unreal future. ${ }^{2}$ This is not a semantic dispute about what 'future' means, but a metaphysical disagreement about what the future is like.

\footnotetext{
${ }^{2}$ Branch-realists are also bound to admit far fewer future histories than anti-realists. If the tree of time had an actual branch for every possible future history then all claims of the form ' $F \varphi$ ' would be true, unless $\varphi$ is impossible. By admitting this many branches, branch-realists would thus be committed to the bizarre claim that all consistent predictions are guaranteed to be successful.
}

Manuscrito - Rev. Int. Fil. Campinas, v. 39, n. 4, pp. 203-223, out.-dez. 2016. 
Returning to the issue of fatalism, suppose that we accept anti-realism about the future, and suppose that X's $\varphi$-ing is contingent. Then $X$ does $\varphi$ in some possible futures and not in others. Hence it is not true, according to the anti-realist, that $X$ will $\varphi$. But part of what it means to say that $X$ is fated to $\varphi$ is that $X$ is going to $\varphi$. So if X's $\varphi$-ing is contingent then $X$ is not fated to $\varphi$. For if $X$ were fated to $\varphi$ then it would be true that he will $\varphi$, and that is not the case, according to the anti-realist. To the extent to which the future is open, agents are therefore not fated to do certain things. In the extreme case where we admit any logically possible future, this means that agents are only fated to do what is logically necessary. As a preliminary result, we can thus note that anti-realism about the future entails anti-fatalism.

\section{Tomorrow's Sea Battle}

The interesting question is whether the converse holds, and whether realism about the future entails fatalism. This is where Aristotle's sea battle argument comes into play. Let ' $F \varphi$ ' be the claim that there will be a sea battle tomorrow and ' $F \neg \varphi$ ' the claim that there will be no sea battle tomorrow. Depending on our epistemic situation, we might well have no evidence for either claim, but if realism about the future is correct then one of them must be true. And if ' $F \varphi$ ' is true, Aristotle reasons, then it must already be determined now that there will be a sea battle. Otherwise, the claim could not already be true. Similarly, if ' $F \neg \varphi$ ' is true then it is already determined that there will not be a sea battle. Either way, the facts about tomorrow's sea battle are already settled, so there is no longer anything that can be done about it by anybody. Aristotle concludes that realism about the future entails radical fatalism. ${ }^{3}$

One way of understanding this argument is as proceeding from realism to fatalism via the intermediate position of what one might call "logical

\footnotetext{
${ }^{3}$ There is disagreement amongst scholars of ancient philosophy about how to interpret the relevant passage in De interpretatione IX, but that is not an issue I want to get into here. I am not interested in Aristotle exegesis but in the connection between realism and fatalism.
}

Manuscrito - Rev. Int. Fil. Campinas, v. 39, n. 4, pp. 203-223, out.-dez. 2016. 
determinism." 'To say that ' $F \varphi$ ' is true now, the logical determinist contends, is to say that there is something about the present that makes it true. Realism about the future would thus entail that all facts about the future are fully determined by facts about the present, and if all facts about the future are fully determined now then there is nothing we can do to alter them. Since the present can no longer be changed, our futures are fully fated. This is a determinist view in that the future would be fully determined by the present, but the determination is not mediated by laws of nature. It would rather be based on a semantic thesis about what it takes for a future tense claim to be true now.

It is perhaps not clear that the present is really as unalterable as this argument suggests. Since the past is over and done with, and since the future has not yet happened, one might argue that the present is the only time that we can change. But there seems to be an easy way around this objection. Suppose that ' $F \varphi$ ' is true now. Then it was the case that $\varphi$ is going to be true. In terms of the past tense operator ' $P$ ' ("it was the case that"), we can write this as ' $P F \varphi$ '. If we now accept the semantic thesis that true past tense claims are made true by the past, then it follows that all truths about the future are full determined by the past, via the theorem schema ' $F \varphi \rightarrow P F \varphi$ ' ("everything that will be true was going to be true"). Since the past can no longer be changed, this means that there is nothing anyone could do between now and tomorrow that would have any impact on whether or not there will be a sea battle. ${ }^{4} \mathrm{~A}$ similar argument would then serve to prove, rather than assume, that the present cannot be changed, either. In this case, we would appeal to the truism that everything that is true was going to be true, ' $\varphi \rightarrow$ $P F \varphi$ '. If that is right then we could only change the present if we could change the past, and that we cannot do.

If these arguments are successful then realism about the future entails radical fatalism, and we can only avoid fatalism by endorsing anti-realism about the future. Together with our preliminary result from Section 2 that anti-realism entails anti-fatalism, this would show that realism about the future and radical fatalism are logically equivalent theses.

\footnotetext{
${ }^{4}$ See also Ryle (1956, ch. 2), Prior (1967, ch. 7), and Diekemper (2004).
}

Manuscrito - Rev. Int. Fil. Campinas, v. 39, n. 4, pp. 203- 223, out.dez. 2016. 


\section{About the Future}

The case for logical determinism presented in the previous section relied on the semantic thesis that true future tense claims are made true by the present. This seems false. Suppose that, while in Sydney, I say "It is raining in Milan." Then my claim is not made true by how things are in Sydney, where I assert it, but by how things are in Milan, which is what my claim is about. Indeed, the very purpose of spatial idioms like 'in Milan' is to achieve just this effect. They allow us to make claims at one place that are about how things are at another. Something similar holds for claims about other times. To a first approximation, future tense claims are about the future. What makes them true are how things will be, not how things are right now. It does not follow from the present truth of "There will be a sea battle tomorrow" that there is something about the present that makes it the case that there will be a sea battle tomorrow. What makes it the case that a sea battle occurs tomorrow is how things are tomorrow, just as the rain in Milan makes it the case that "It is raining in Milan" is true when uttered in Sydney.

I do not mean to suggest that every future tense claim is about the future, or that every past tense claim is about the past. A future-tense claim ' $F \varphi$ ' can fail to be about the future if $\varphi$ itself contains past tense operators, and a pasttense claim ' $P \varphi$ ' can fail to be about the past if $\varphi$ contains future tense operators. In particular, the past tense claim that there was going to be sea battle tomorrow is as much about the future as the future tense claim that there will be sea battle tomorrow. Hence the truth of ' $F \varphi$ ' or ' $P F \varphi$ ' alone does not entail that there is something about the present or the past, respectively, that makes it the case that $\varphi$ will obtain. If that is right then realism about the future does not entail logical determinism.

Before proceeding, I should note that there are some philosophers who do indeed believe that all true past and future tense claims are about the present. An obvious example are presentists, who claim that only present objects exist. Presentists face the problem of what to say about otherwise unproblematic claims like "There were dinosaurs" or "There will be space stations on Mars." Since they cannot reject all such claims without undermining the plausibility of their position, many presentists resort to the stratagem of arguing that past and future tense claims are about present objects. One version is the Lucretian presentism advocated by John Bigelow

Manuscrito - Rev. Int. Fil. Campinas, v. 39, n. 4, pp. 203-223, out.-dez. 2016. 
(1996), who claims that what makes "There were dinosaurs" true is that the aggregate of all presently existing objects has the property of being-such-thatthere-were-dinosaurs. I do not think that this is a particularly plausible view about the meaning of past and future tense claims, but this is not a point I want to press here. Our question is whether a realist about the future is committed to fatalism, and there is no theoretical pressure for such a realist to adopt a revisionist view about future tense claims. Realists about the future are not presentists, and they can easily rebut the claim that their view entails logical determinism by rejecting the implausible semantic thesis that all future tense claims are made true by the present.

\section{Won't Isn't Can't}

One might reply that the sea battle argument does not need the intermediate step of logical determinism to get from realism about the future to radical fatalism. Never mind the question of what future tense claims are about. If ' $F \varphi$ ' is true then it is inevitable that $\varphi$ will come to pass, for otherwise the truth of ' $F \varphi$ ' would not already be settled. That alone gives us fatalism. Michael Dummett (1964, p. 345) describes an argument like this, which was popular during the bombing of London in the Second World War:

Either you are going to be killed by a bomb or you are not going to be. If you are, then any precautions you take will be ineffective. If you are not, all precautions you take are superfluous. Therefore it is pointless to take precautions.

By what mechanism truths about future would become inevitable might not be clear. But someone who wishes to deny realism because it would lead to radical fatalism could plausibly reject any demand that she provide an account of this. Spelling out the details of this inevitability would be the job of the realist about the future, not the anti-fatalist anti-realist.

In any case, the flaw in the bombing argument is easily identified. To say that you are fated to $\varphi$ is to say that you cannot avoid $\varphi$, and not merely that you will not avoid it. Fatalism is a modal thesis. If you cannot avoid $\varphi$ then you will not avoid $\varphi$, but the converse does not hold. You might be too lazy

Manuscrito - Rev. Int. Fil. Campinas, v. 39, n. 4, pp. 203-223, out.-dez. 2016. 
to avoid $\varphi$, or not care enough to do anything about it. In the case of the bombing, it might be that you are going to die because you are not going take any precautions (even though you could have). Or it might be that you are not going to die because you are going to hide in a shelter (even though you could not have). We only get the conclusion that you are fated to do whatever it is that you will do if we already assume that there is nothing that you can do about the future-which is the fatalist thesis that the argument was supposed to establish.

Similar remarks apply to the relation between realism about the past and fatalism. Without further argument, it does not follow that everything that has happened was fated. There might have been things that you could have avoided that you did not avoid because they were too unimportant to bother with, or because you did not have any preferences either way. Just because you did not care on which side of the bed you slept does not mean that you were fated to sleep where you did sleep. It might also be that you did not avoid what happened to you because it was exactly what you wanted. You did not pass your $\mathrm{PhD}$ defense because you were fated to do so, but because you wanted to pass, and avoided any other course of action that would have prevented you from achieving your aim.

Realism about the future does indeed entail that either ' $F \varphi$ ' or ' $F \neg \varphi$ ' is true, but the truth of ' $F \varphi$ ' alone does not tell us whether $\varphi$ can be avoided any more than the truth of ' $P \varphi$ ' tells us whether $\varphi$ could have been avoided. All that ' $F \varphi$ ' tells us is that $\varphi$ won't be avoided, and won't isn't can't.

\section{Laws and the Future}

Instead of appealing to logical determinism, one might argue that realism about the future must be underwritten by deterministic laws of nature. Say that a claim is historically necessary just in case it is a logical consequence of the history of the world up to the present moment and the laws of nature. Any true claim about the past then automatically counts as historically necessary, but perhaps not every claim about the future. To the degree to which the laws of nature are indeterministic, we can distinguish different historically possible futures that differ from one another in the truth-values that they assign to historically contingent claims.

Manuscrito - Rev. Int. Fil. Campinas, v. 39, n. 4, pp. 203-223, out.-dez. 2016. 
If we now stipulate that ' $F \varphi$ ' is true just in case $\varphi$ is true in all historically possible futures then we only get realism about the future if there is exactly one historically possible future. Otherwise, there would be claims $\varphi$ such that neither ' $F \varphi$ ' nor ' $F \neg \varphi$ ' is true. And to say that there is exactly one historically possible future is to say that everything about the future is a logical consequence of the laws of nature and the history of the world up to the present moment, which is tantamount to saying that the laws of nature are deterministic. This is not the same argument as the one that we earlier attributed to Aristotle. The present argument suggests that realism about the future pre-supposes a nomical determinism that is mediated by the laws of nature, rather than a logical determinism that follows from an implausible semantic thesis about the subject matter of future-tense claims.

When discussing the bombing of London, we distinguished the claim that you will not avoid being killed by a bomb and the seemingly stronger claim that you cannot avoid it. If you cannot avoid something then it will happen, but I suggested that the converse claim is not true, and that there might be things that you could avoid that you will not avoid. Robert McArthur (1974) notes that the current setup leaves no room for such a distinction between what will be and what must be. If determinism is true then there is only one historically possible future, and everything about it is historically necessary. And if determinism is false then the only future tense claims that are true are those that are true in all historically possible futures because that is how we defined the future tense operator. We again get the conclusion that all true future tense claims are historically necessary. Whatever will be will be so necessarily, independently of whether determinism is true. The distinction between won't and can't collapses.

However, McArthur only arrives at this conclusion by assuming antirealism about the future from the outset, and by treating determinism as nothing but a degenerate case of anti-realism. The link between what is future and what is historically necessary was not derived from other principles, but can be easily traced to the anti-realist semantics we adopted for the future tense operator, which has ' $F$ ' quantify over all historically possible futures. Given such a set-up, there can be no indeterminism without an open future with multiple future branches. This might tell us how an anti-realist should think about determinism, but it is irrelevant to the question that we are considering here. The issue at stake is whether a realist about the future can

Manuscrito - Rev. Int. Fil. Campinas, v. 39, n. 4, pp. 203-223, out.-dez. 2016. 
accept indeterminism, and we cannot expect an illuminating answer to this question if we assume an anti-realist setup.

\section{The Thin Red Line}

To show that realism about the future and indeterminism are indeed compatible, consider a version of the "thin red line" semantics for a logic that contains both a future tense operator ' $F$ ' and an historical necessity operator ' $\square$ '. A claim $\varphi$ is historically necessary, $\square \varphi$, if and only if $\varphi$ follows from the laws of nature and the history of the world up to the present. A thin red line model for such a logic then contains a range of possible futures that are used to interpret the historical necessity operator. A claim is historically necessary just in case it is true in all such possible futures. This might look similar to McArthur's setup, but the difference is that we do not adopt an anti-realist reading of the future tense operator, which would amount to giving ' $F$ ' the same semantics as ' $\square$ '. Instead, we single out one of the possible futures of the model as the actual future of the model (the "thin red line") and then count ' $F \varphi$ ' as true if and only if $\varphi$ is true at some time in this one future history. While the historical necessity operator quantifies over all possible futures, the future tense operator only acts along the thin red line. ${ }^{5}$

If we accept such a realist account of the future then it only follows that all true claims about the future are historically necessary if the laws are deterministic. If the laws are indeterministic then there are many claims that will be true (on the thin red line) that are not historically necessary because

\footnotetext{
5 The term 'thin red line' is due to Belnap and Green (1994), but the semantics itself had been discussed before, notably by Øhrstrøm (1984). I should also note that Belnap and Green are concerned with the temporal aspect of speech acts and predictions. Most objections to the thin red line semantics concern its use in such a linguistic theory of temporal discourse. Such objections are irrelevant to the present application, which employs the thin red line semantics to make a metaphysical point about the compatibility between realism about the future and indeterminism. Much of the recent literature on the thin red line does not distinguish these two issues as clearly as it should. See also MacFarlane (2003, 2008), Torre (2011), and Correia and Iacona (2013).
}

Manuscrito - Rev. Int. Fil. Campinas, v. 39, n. 4, pp. 203-223, out.-dez. 2016. 
they are not true in all possible futures. This gives us a picture that is realist about the future without being deterministic, and shows that the future does not need to be open to get a lack of determinism. All that we need for ' $F \varphi$ ' and ' $\square \varphi$ ' to come apart are the other possible futures, not the openness of the future. Indeterminism only requires that other possible futures are realized in other possible worlds; there is no need to import them into the actual world, as an advocate of the open future would do. ${ }^{6}$

At this juncture, one might wonder whether anti-realism about the future is even a coherent position. The open future view does not claim that time has come to an end, and that we are now at the last moment in history. It holds that one of the possible future histories will be the actual future. We might be in no position to figure out now what the actual future is like, and the actual future might not even be causally determined by the past. But we must not confuse the question or whether the future is causally or epistemically necessary with the question of whether it exists at all. Unless the present moment marks the end of time, there is an actual future that can serve as the thin red line for a future tense operator to range over.

I think we ought to distinguish anti-realism about the future from the more innocuous thesis that the future is open. The straightforward way of understanding the openness of the future is in terms of historical necessity. To say that the future is open is to say that there are many historically possible futures, and that it has not yet been settled which of them will be the actual future. If the future were already settled by the laws of nature and the history of the world up to now then there would be only one historically possible future. On this view, the future is open if and only if the laws of nature are not deterministic.

Anti-realism supplements the open future view-which is about historical necessity — with a somewhat bizarre claim about the future tense operator. It claims that none of the possible futures is the actual future, and that the only true future tense claims concern things are true in all possible futures. This

\footnotetext{
${ }^{6}$ In Lewis (1986, p. 206f.), this is the contrast between branching and divergence. Branching concerns a single possible world that has a branching time-series; divergence refers to cases where multiple possible worlds with linear time-series possess indistinguishable initial segments. Barnes and Cameron (2009) defend a similar account.
}

Manuscrito - Rev. Int. Fil. Campinas, v. 39, n. 4, pp. 203-223, out.-dez. 2016. 
strikes me as incoherent as endorsing a theory of possibility that admits numerous possible worlds, but denies that any of them is actual. If that is right then even the preliminary result from the end of Section 2 looses all interest, since it establishes anti-fatalism as the consequence of an incoherent theory about the future.

\section{The Origins of Fate}

My aim so far has been to separate fatalism from realism about the future. If this attempt was successful then fatalism is not an issue that philosophers of time need to worry about, but this does not show that fatalism is not an important metaphysical thesis. I have tacitly identified fatalism with determinism, and determinism is surely a thesis of metaphysical interest. I now want to retract this concession, and argue that we also need to distinguish the question of whether $X$ is fated to $\varphi$ from the question of whether $X$ 's $\varphi$ ing was determined by an earlier state of the world. Fatalism and determinism are two distinct theses.

Suppose that $X$ will $\varphi$. What does it mean to say that $X$ is fated to $\varphi$ ? As a first attempt, one might propose that $X$ is fated to $\varphi$ just in case there is no action $\alpha$ that $X$ could perform that would prevent his $\varphi$-ing; that is, no action $\alpha$ such that, were $X$ to perform $\alpha$ at an appropriate time, he would not $\varphi$. However, the prevention of $\varphi$-ing might not require a single intervention, but a sequence of coordinated actions $\alpha_{1}, \alpha_{2}, \ldots, \alpha_{n}$ such that the performance of all of these actions, in this order, would prevent X's $\varphi$-ing. Let us call such a coordinated sequence of actions a strategy. We might then say that $X$ is fated to $\varphi$ just in case there is no strategy that $X$ could execute that would prevent his $\varphi$-ing.

On this view, fate can have a number of different sources. It might be that the laws of nature are such as to prevent $X$ 's $\varphi$-ing. It is our fate that we shall travel at velocities below the speed of light since the laws of nature do not permit us to do otherwise. One's fate can also depend on the laws of logic and mathematics. If $X$ decided to devote his life to writing a computer program that checks whether any other computer program will run into an infinite loop then his life is fated to end in failure because the Halting Problem

Manuscrito - Rev. Int. Fil. Campinas, v. 39, n. 4, pp. 203-223, out.-dez. 2016. 
has no solution. Similar remarks apply to a life plan of composing a rectangle from a prime number of square tiles.

It might also be that $X$ is fated to $\varphi$ because some powerful agent $Y$ has decreed that $X$ shall $\varphi$, and will respond to any attempt at avoiding $\varphi$ on the part of $X$ with a suitable counter-action. In such a case, the source of $X$ 's fate is that he is playing against a stronger competitor. For every strategy that $X$ might try to execute to avoid $\varphi$-ing, $Y$ has a counter-strategy that will lead back to $X$ 's $\varphi$-ing. Note that $Y$ need not be omnipotent, nor does she need to have decreed everything about $X$ 's life. The situation of $X$ might be like that of a pug on a leash. The pug has some freedom of action, but will lose any contest in which it tries to act against the wishes of its owner. The owner is not omnipotent, just more powerful than the pug. In this case, we might describe $X$ 's fate by saying that he is meant to $\varphi$ in the literal sense that some other agent $Y$ intends him to do so.

I think this account of fate is roughly on the right track, but it might still not be quite what we want. Fate is sometimes due to unfavorable circumstances. If $X$ was born a peasant in the fifteenth century then $X$ 's fate was to endure the "idiocy of rural life" (as the Communist Manifesto so aptly puts it). There is also the possibility that $X$ acquires a fate by painting himself into a corner, by creating the unfavorable circumstances himself. Some things might be fated at one time that were not fated earlier. It was not always $X$ 's fate, but, after decades of chain-smoking, it is now his fate to die of lung cancer; there is no longer any strategy he could execute to avoid it. Yet in neither of these cases would it be completely impossible for the agent to avoid their fate. By committing suicide, one can easily avoid both lung cancer and the idiocy of rural life. So we might have to alter the notion of a possible strategy a little bit, so as to exclude strategies that would be incompatible with the overriding desires of the agent.

We might also have to take the options of by-standers into account. Suppose you walk past a shallow frozen pond, where an unattended infant has just broken through the thin ice. Inspired by our account, one might say that it is the infant's fate that he shall drown because there is no strategy that he could execute that would prevent it. That seems wrong, for you could easily wade into the knee-deep water and save the child. One might therefore suggest that $X$ is fated to $\varphi$ just in case there is no strategy that anyone could perform that would prevent it. Yet it is not obvious that this is right, either.

Manuscrito - Rev. Int. Fil. Campinas, v. 39, n. 4, pp. 203-223, out.dez. 2016. 
For example, we could no longer say that $X$ is fated to $\varphi$ because some powerful agent $Y$ ensures that he does so, since $Y$ could just change her mind about what she wants $X$ to do.

The details of an analysis of fate might thus end up being rather complex, but they are unlikely to alter the central point that fate is a matter of preventability, and that fate depends on the modal question of what actions agents could have performed instead of the ones they actually perform. This helps to explain why the possible sources of fate form such an inhomogeneous group: they are a subset of the sundry factors that determine the truth of counterfactual claim more generally. Counterfactuals depend on the laws of logic and mathematics, but also on the laws of nature, and on contingent features of the context in which the counterfactual is being evaluated. What an agent can do depends on his situation.

\section{Random Fate}

Those who want to identify fatalism with determinism might say that what unifies these seemingly unrelated sources of fate is historical necessitation. While there might be many sources of fate, they argue, there is only one relation of fatedness. What makes X's $\varphi$-ing fated is that it is determined by previous states of the world. To support this claim, one might appeal to Peter van Inwagen's (1975) argument for the incompatibility of determinism and freedom of action. If $X$ 's actions are a logical consequence of the laws of nature and the past state of the world, van Inwagen argues, then $X$ could not have performed any action other than the one he actually performs. For $X$ to act differently, he would have to be able to change the laws of nature, or the past state of the world, and he cannot do either. It seems to follow that radical fatalism is true in every possible world in which the laws of nature are deterministic. If $X$ does $\varphi$ in a deterministic world then he cannot avoid $\varphi$ ing for the simple reason that he cannot act any differently from the way he actually acts.

To see the problem with this argument, consider a scenario in which determinism is false. If $X$ 's $\varphi$-ing is not determined then whether or not $X$ does $\varphi$ is a matter of chance. He does $\varphi$ in some historically possible futures and he does not do $\varphi$ in others. Suppose that $X \operatorname{does} \varphi$ in the actual future.

Manuscrito - Rev. Int. Fil. Campinas, v. 39, n. 4, pp. 203-223, out.-dez. 2016. 
Then $X$ will $\varphi$ and there is nothing that he could do that would prevent it. Due to the chancy nature of the world, there is no action whose performance would guarantee the truth of ' $\neg \varphi$ '. If $X$ were to perform different acts than the ones he will actually perform then a different possible future would be actual. In that other possible future, his $\varphi$-ing might indeed turn out differently than in the actual future. But there is nothing that $X$ could do that would guarantee that such a possible future will be actual, and thus nothing he could do to prevent $\varphi$. Luck isn't prevention. ${ }^{7}$

This means that a lack of determinism does not yield a lack of fatalism. Every random $\varphi$-ing is fated because it is unavoidable. This shows that fatalism does not entail determinism, and it also serves to cast doubt on the van Inwagen-inspired argument for the converse conclusion that determinism entails fatalism. If we accepted that argument then radical fatalism would be a necessary truth. If determinism is true then fatalism follows because of the van Inwagen argument, and if determinism is false then fatalism follows because all random actions are fated. Radical fatalism would be a trivial thesis.

One might suggest that this merely shows that we need to reconsider the way we interpret the 'can' in the claim that $X$ is fated to $\varphi$ just in case he cannot avoid it. Van Inwagen takes it for granted that $X$ can only do what is historically possible, which trivializes fatalism. An alternative account is David Hume's (1777, sec. VIII, \ 73) "hypothetical liberty," according to which an agent $X$ can perform an action $\alpha$ just in case, had $X$ decided to $\alpha$ then he would have. On a possible-world account of counterfactual conditionals, this requires the closest possible world in which $X$ decides to $\alpha$ to be one in which

\footnotetext{
${ }^{7}$ At the end of Section 2, we concluded that $X$ is not fated to $\varphi$ if $\varphi$ is true in some possible futures, and false in others. We now concluded that, in an indeterministic world, $X$ is fated to $\varphi$ if $\varphi$ is true in the actual future, and false in to some other historically possible future. These seemingly contradictory results are compatible because they assume different accounts of the future-tense operator. Section 2 adopted an anti-realist semantics and concluded that $X$ is not fated to $\varphi$ because ' $F \varphi$ ' is not true on such a semantics, and not because $X$ 's $\varphi$-ing is in any sense up to him. In the current setup, where either ' $F \varphi$ ' or ' $F \neg \varphi$ ' is true on the thin red line, $X$ is fated to do whatever it is that he will do because his doing so is random. There is nothing that he can do that would prevent it.
}

Manuscrito - Rev. Int. Fil. Campinas, v. 39, n. 4, pp. 203-223, out.-dez. 2016. 
he does $\alpha$. In this sense, $X$ can do things that are historically impossible. Suppose that, in the actual world, $X$ decides not to $\alpha$, does not perform $\alpha$, and that both of these events - the deciding and the not doing-are fully determined by the previous states of the world so that both are historically necessary. When we ask whether $X$ would have done $\alpha$, had he decided to do so, we are thus considering a counterfactual scenario that is not historically possible because his not wanting to $\alpha$ is historically necessary. This also means that $X$ 's $\varphi$-ing can be fully determined without it being fated. An agent $X$ can avoid $\varphi$-ing, by performing some strategy $\alpha_{1}, \alpha_{2}, \ldots, \alpha_{n}$, even though there is no historically possible future in which he performs any of these actions.

Part of what is at stake here is the familiar debate about the relation between freedom of action and determinism. Incompatibilists like van Inwagen claim that one rules out the other, while compatibilists like Hume argue that determinism permits freedom of action. No matter which position we endorse, fatalism fails to coincide with determinism. If we spell out 'can' in terms of historical possibility then fatalism is trivial, and determinism is not. If we spell out 'can' in terms of Hume's hypothetical liberty then we can have determinism without fatalism. We can also have fatalism without determinism because random actions would still be fated.

\section{Conclusion}

In the beginning of the paper, I characterized fate in terms of avoidability. It is perhaps not obvious that this is correct way of thinking about the matter. Offhand, there are three different things that could be meant by saying that $X$ is fated to $\varphi$ :

(a) $X$ cannot avoid $\varphi$-ing.

(b) X's $\varphi$-ing is determined by previous states of the world.

(c) Someone else intends $X$ to $\varphi$ and ensures that he does.

These conditions can easily come apart. If we read 'can' in terms of Hume's hypothetical liberty then $X$ 's $\varphi$-ing might be fully determined, but

Manuscrito - Rev. Int. Fil. Campinas, v. 39, n. 4, pp. 203-223, out.-dez. 2016. 
both avoidable and unintended by anyone. A random $\varphi$-ing would be unavoidable but undetermined, and could not be ensured by anyone's intentions. Of the three, (a) strikes me as the most plausible account, and it is fatalism in this sense that this paper was about. We already have a good term for (b), 'determinism', and there seems to be no point in wasting another word on this.

Those who think that it is part of the meaning of 'fate' that fates are preordained might find (c) more appealing, but that does not turn fatalism into an interesting metaphysical thesis, either. The degree of fatalism would merely reflect the extent to which agents take an interest in one another, and have the power to enforce their preferences. There might be more urgency to this question if the agents who are doing the intending and enforcing include powerful gods. But while the existence of gods is of ontological interest, fatalism in the sense of (c) would still only make a difference to our metaphysics if there were something metaphysically special about the gods' plans. Otherwise, there would be nothing to distinguish their manipulation of our futures from those of other humans who meddle in our affairs.

In most religions, the revealed wishes of the gods are decidedly arbitrary. There does not seem to be any compelling reason why we should rest every seven days, rather than every five or thirteen, or why we should not direct the Hajj to Sydney, which has better weather than Mecca. These might be theologically weighty questions, but they do not seem to matter to metaphysics. Of course, even believers do not follow all of these divine commandments, but also the actual history of the universe, as described by religious traditions, seems to be rather capricious. The stories of gods and mortals might possess wonderful narrative unity, like a good novel, but they do not seem to reflect anything of great metaphysical importance.

Gottfried Willhelm Leibniz famously thought that ours is the best of all (logically) possible worlds, and that God-whom Leibniz believed to exist necessarily-could not have failed to create precisely this possible world. If that were right then fate would be part of the all-encompassing reason that determines all aspects of reality. Every feature of everybody's life would make an essential contribution of the maximal goodness of the world, and nobody could have done anything differently since that would have led to a suboptimal world. Whenever $X$ does $\varphi$, it would be (metaphysically) impossible for him to do anything else. This might turn fatalism into a metaphysically

Manuscrito - Rev. Int. Fil. Campinas, v. 39, n. 4, pp. 203-223, out.dez. 2016. 
interesting thesis, but only at the cost of assuming an utterly implausible rationalist metaphysics, as noted by Voltaire (1759).

If we put such Panglossian views aside, then our prudential interest in divinely ordained fate is no different from our interest in the wishes of other powerful agents. So I will stick to my account, which regards unavoidability as the hallmark of fate. Fate reflects how an agent is situated vis-à-vis a range of natural conditions that include the laws of nature, contingent matters of facts, and the conditions and intentions of other agents. Fate might sometimes involve some features that are of metaphysical interest - such as the truth of determinism or the existence of an all-powerful God-but it is not itself an interesting metaphysical thesis. What is or is not part of our own fate might be important to how we lead our lives, but it does not matter to our metaphysics. Unlike the division of possible worlds into deterministic and indeterministic ones, there is no metaphysically interesting division of possible worlds into fatalist and non-fatalist worlds.

\section{References}

BARNES, E. and CAMERON, R. "The open future: bivalence, determinism and ontology”, Philosophical Studies, vol. 146, pp. 291-309, 2009.

BELNAP, N. and GREEN M. "Indeterminism and the thin red line", Philosophical Perspectives, vol. 8, pp. 365-388, 1994.

Bigelow, J. "Presentism and properties", Philosophical Perspectives, vol. 10, pp. 35-52, 1996.

BOURNE, C. "Future contingents, non-contradiction, and the law of excluded middle muddle", Analysis, vol. 64, pp. 122-128, 2004.

Correia, F. and Iacona, A. (eds.). Around the Tree: Semantic and Metaphysical Issues Concerning Branching and the Open Future. Dordrecht and New York: Springer, 2013.

Diekemper, J. "Temporal necessity and logical fatalism", Proceedings of the Aristotelian Society, vol. 104, pp. 289-296, 2004.

Manuscrito - Rev. Int. Fil. Campinas, v. 39, n. 4, pp. 203-223, out.-dez. 2016. 
DummeTt, M. "Bringing about the past”, Philosophical Review, vol. 73, pp. 338359, 1964.

Goodman, N. ““About' mistaken”, Mind, vol. 74, p. 248, 1965.

Hume, D. Enquiries Concerning Human Understanding and Concerning the Principles of Morals. London: T. Cadell, 1777.

LEWIS, D. On the Plurality of Worlds. Oxford: Blackwell, 1986.

ŁUKASIEWICZ J. "On determinism," in Selected Works (pp. 110-128). Amsterdam: North-Holland, 1970.

MACFARlane, J. "Future contingents and relative truth", Philosophical Quarterly, vol. 53, pp. 321-336, 2003.

MACFARLANE, J. "Truth in the garden of forking paths," in M. Kölbel and M. García-Carpintero (eds.). Relative Truth (pp. 81-102). Oxford: Clarendon Press, 2008.

MCARTHUR, R. "Factuality and modality in the future tense", Noûs, vol. 8, pp. 283-288, 1974.

ØHrstrøм, P. “Anselm, Ockham and Leibniz on divine foreknowledge and human Freedom”, Erkenntnis, vol. 21, pp. 209-222, 1984.

PRIOR, A. "Three-valued logic and future contingents", Philosophical Quarterly, vol. 3, pp. 317-326, 1953.

Prior, A. Past, Present and Future. Oxford: Clarendon Press, 1967.

Putnam, H. "Formalization of the concept 'about", Philosophy of Science, vol. 25, pp. 125-130, 1958.

ResCHER, N. "A note on 'about”, Mind, vol. 72, pp. 268-270, 1963.

RYLE, G. Dilemmas. Cambridge: Cambridge University Press, 1956.

THOMASON, R. "Some completeness results for modal predicate calculi", in K. Lambert (ed.). Philosophical Problems in Logic (pp. 56-76). Dordrecht: Reidel, 1970.

Tooley, M. Time, Tense, and Causation. Oxford: Clarendon Press, 1997.

Manuscrito - Rev. Int. Fil. Campinas, v. 39, n. 4, pp. 203-223, out.-dez. 2016. 
TORRE, S. “The open future,” Philosophy Compass, vol. 6, pp. 360-373, 2011.

VAN INWAGEN, P. "The incompatibility of free will and determinism," Philosophical Studies, vol. 25, pp. 185-199, 1975.

Voltaire Candide, ou l'Optimisme. Paris, 1759.

YABLO, S. Aboutness. Princeton: Princeton University Press, 2014.

Manuscrito - Rev. Int. Fil. Campinas, v. 39, n. 4, pp. 203-223, out.-dez. 2016. 